\title{
A PARTICIPAÇÃO DO PODER LEGISLATIVO NO PLANEJAMENTTO PÚBLICO MUNICIPAL: ANÁLISE DAS PROPOSTAS DE EMENDAS PARLAMENTARES ÀS LEIS ORÇAMENTÁRIAS DE CURITIBA
}

\author{
Priscila Perelles* \\ Antonio Gonçalves de Oliveira* \\ Ivan Carlos Vicentin* \\ Rogério AllonDuenhas* \\ *Universidade Tecnológica Federal do Paraná, Programa de Pós-graduação em Planejamento e Governança \\ Pública, Curitiba, PR, Brasil
}

\begin{abstract}
Resumo
Norteado pelo objetivo de analisar o quantitativo e as características das emendas convertidas em lei e pela discussão sobre a problemática do distanciamento dos parlamentares das funções legislativas em matéria orçamentária, este artigo aborda a participação do Poder Legislativo no planejamento público sob a perspectiva de legitimação social em democracias representativas. O referencial teórico que a ele dá substrato remete ao processo de planejamento público e à política orçamentária com foco nas emendas parlamentares. O percurso metodológico evidencia a pesquisa como aplicada e delineada como estudo de caso, com enfoque descritivo. O método empregado é estatístico descritivo. Os resultados apontam i) que o déficit de conhecimento técnico, as assimetrias de informação e a baixa qualidade da transparência empregada nas propostas de orçamento perpetuam a hegemonia do Executivo e ii) que não houve alterações dessa estrutura pela adoção de emendas impositivas ao orçamento anual.

Palavras-chave

Planejamento Urbano; Orçamento; Poder Legislativo; Emendas Parlamentares.
\end{abstract}




\title{
THE PARTICIPATION OF THE LEGISLATIVE POWER IN MUNICIPAL PUBLIC PLANNING: ANALYZING PROPOSALS FOR PARLIAMENTARY AMENDMENTS TO THE BUDGET LAWS IN CURITIBA
}

\author{
Priscila Perelles* \\ Antonio Gonçalves de Oliveira* \\ Ivan Carlos Vicentin* \\ Rogério AllonDuenhas* \\ *Universidade Tecnológica Federal do Paraná, Programa de Pós-graduação em Planejamento e Governança \\ Pública, Curitiba, PR, Brazil
}

\begin{abstract}
Guided by the goal to analyze the amount and the characteristics of amendments converted into law and by the discussion about the parliamentarians' detachment from the legislative functions on budget matters, this article approach Legislative Power's participation on public planning under social legitimation perspective in representative democracies. Theoretical reference that supports it remits to the process of public planning and to the budget politics focusing on parliamentary amendments. Its methodological path emphasizes an applied research outlined as a case study with descriptive approach. The method employed is descriptive statistic. The results point that i) technical knowledge deficit, information asymmetry and low quality transparency on budget's proposals perpetuates Executive Power's hegemony and ii) there was no modifications on that structure by the adoption of impositive amendments to the annual budget.
\end{abstract}

Keywords

Urban Planning; Budget; Legislative Power; Parliament's Amendment. 


\title{
A PARTICIPAÇÃO DO PODER LEGISLATIVO NO PLANEJAMENTO PÚBLICO MUNICIPAL: ANÁLISE DAS PROPOSTAS DE EMENDAS PARLAMENTARES ÀS LEIS ORÇAMENTÁRIAS DE CURITIBA
}

\author{
Priscila Perelles \\ Antonio Gonçalves de Oliveira \\ Ivan Carlos Vicentin \\ Rogério AllonDuenhas
}

Introdução

No Brasil, como na maioria dos países latino-americanos, por fatores históricos de descobrimento e colonização, invertendo a visão aristotélica, o Estado antecedeu a formação da sociedade. Isso resultou na adoção de modelo federativo centralizado, em que estados e municípios, loci originários de formação da sociedade, são submetidos e dependentes do poder central, que a rigor seria coadjuvante na federação. Essa condição organizacional do Estado brasileiro, nas palavras de Matias-Pereira (2010), é refletida em estruturas de poder concentradas e excludentes e em processos de tomada de decisões tecnocráticos, hierárquicos e formais que limitam a construção democrática e o desenvolvimento equitativo.

Não obstante, as cidades têm elevado peso na construção do planejamento público, haja vista os efeitos positivos do relacionamento entre desenvolvimento urbano e econômico-social. Por isso, economistas e urbanistas convergem no que diz respeito à ideia de que desenvolvimento urbano sustentável e políticas urbanas são instrumentos potencializadores das vantagens da urbanização e determinantes tanto para a sustentabilidade na América Latina como para o desenvolvimento nacional e global (CEPAL, 2016; FLORIDA, 2016).

O desenvolvimento local, todavia, não resulta apenas do plano de desenvolvimento nacional. Ele decorre, principalmente, das políticas públicas adotadas pela administração municipal. Se estas não forem convergentes com esse objetivo, o 
resultado será a estagnação ou a involução. A pesquisa de Coimbra e Kopfer (2017) evidencia efeitos positivos à coletividade alcançados por política pública local desenvolvimentista eficiente.

Essa, no entanto, não é a regra. O planejamento urbano nas últimas décadas tem sido atrasado pela ineficiência dos marcos institucionais vigentes. A Comissão Econômica para a America Latina e o Caribe (Cepal) aponta a necessidade de implantação de governança complexa e integrada das cidades e dos sistemas metropolitanos para que os instrumentos de planejamento urbano sejam capazes de coordenar os diversos níveis de governo e também a relação do Estado com a sociedade civil e o setor privado (CEPAL, 2016).

O sistema brasileiro de planejamento governamental delineado pela Constituição Federal de 1988 (CF/88) é uma "cartilha de planejamento em três etapas", formalizadas em leis orçamentárias, reeditadas periodicamente: i) o Plano Plurianual (PPA), com vigência de quatro anos; ii) a Lei de Diretrizes Orçamentárias (LDO); e iii) a Lei Orçamentária Anual (LOA). A periodicidade obrigatória orienta a constante avaliação, debate e revisão de objetivos para manter o curso do desenvolvimento (COIMBRA; KOPFER, 2017). Em razão da organização político-administrativa da federação, esse sistema é intergovernamental, coexistindo em três níveis de governo: União, estados e municípios (MATIAS-PEREIRA, 2010). Nesse matiz, o bom planejamento depende da formação dessa rede de governança nas três escalas para que sejam identificados os problemas e as oportunidades mais relevantes e definidas as melhores soluções com efeitos multiplicadores a serem implantadas (PALUDO; PROCOPIUCK, 2014).

Nas palavras de Moleta (2017), no entanto, o compromisso de alinhamento intergovernamental ainda representa grande desafio de articulação e não costuma ser observado. Confrontando os PPAs nacional, estaduais e das capitais, evidenciou-se que os planos de governos, em sua maioria, não possuíam agendas comuns; e os orçamentos analisados, pouco transparentes, não correspondiam a efetivo planejamento de curto, médio e longo prazos. Na mesma toada, Dornellas (2015) aponta que o planejamento público brasileiro também enfrenta desafios de alinhamento entre as peças orçamentárias na mesma escala de governo e o baixo comprometimento da Administração com as metas e diretrizes traçadas.

Assim, Dornellas (2015) e Moleta (2017) convergem ao expor a realidade fática de que o planejamento governamental, traduzido em leis orçamentárias, ainda é relegado a um papel secundário na gestão pública, associado mais a formalidades do que a efeitos concretos. Para inferir confiabilidade ao planejamento, seria necessário adotar princípios de governança pública, como transparência, 
responsabilidade, ética e prestação de contas, além de aumentar o envolvimento democrático no processo a fim de legitimá-lo sob a perspectiva social (MOLETA, 2017).

Nessa perspectiva de legitimação social do planejamento governamental, insere-se a discussão sobre a participação do Legislativo no sistema orçamentário em democracias representativas. A CF/88, ao atribuir competência ao Poder Executivo para a elaboração das leis orçamentárias, transfere-lhe parcela da função típica do Legislativo. Mesmo tendo sido resgatada pelo constituinte de 1988 a prerrogativa parlamentar para propor emendas na fase legislativa do ciclo orçamentário, o alcance dessa participação é reduzido.

A fase legislativa do planejamento público ainda é pouco explorada nas doutrinas e pesquisas científicas, com o predomínio de temas de elaboração e execução do planejamento pelo Poder Executivo, do orçamento participativo e de políticas públicas atendidas pelas emendas parlamentares. Máxime então que este artigo discute a problemática do distanciamento dos parlamentares das funções legislativas em matéria orçamentária por meio da medição de assertividade das emendas parlamentares às leis orçamentárias de Curitiba; seu objetivo norteador consiste em analisar o quantitativo e as características das emendas parlamentares que foram convertidas em lei, reconhecendo-se que tais propostas são o instrumento de participação popular no planejamento governamental pela via representativa.

1. Referencial teórico

1.1 Planejamento público e orçamento

Até a década de 1980, os planos de desenvolvimento brasileiros eram centralizados, fechados à participação social, imediatistas e intervencionistas, pouco técnicos e de cunho eminentemente econômico, tidos como função alheia ao Parlamento. A CF/88 inaugurou um novo paradigma de sistema de planejamento governamental ao estabelecer um conjunto integrado de ferramentas formadas pelos planos e programas nacionais, regionais e setoriais e pela tríade do sistema orçamentário: PPA, LDO e LOA (MATIAS-PEREIRA, 2010; PALUDO; PROCOPIUCK, 2014).

Apesar de instituídos em 1988, os instrumentos de planejamento orçamentário somente foram implementados após a regulamentação pelo Decreto Federal $\mathrm{n}^{\circ}$. 2.829, de 29 de outubro de 1998. Ascendeu, então, a importância do planejamento, que passou a ser suscitado em diversas normas associadas à gestão pública. Nessa toada, a Lei Complementar Federal $n^{\circ}$. 101, de 4 de maio de 2000, chamada Lei de Responsabilidade Fiscal (LRF), dispõe que a ação planejada e transparente é pressuposto da gestão fiscal responsável; e a Lei Federal $n^{\circ}$. 10.257, de 10 de julho de 2001, ao disciplinar o Estatuto da Cidade, estabeleceu regras relacionadas ao PPA para os municípios que devem, obrigatoriamente, incorporar as diretrizes e 
prioridades do Plano Diretor para uniformizar os objetivos urbanos com o plano de investimentos e aplicar a gestão orçamentária participativa em sua elaboração (COIMBRA; KOPFER, 2017).

O planejamento público tornou-se, pois, como expõe Matias-Pereira (2010), um instrumento de caráter imperativo e permanente da gestão pública, desenvolvido em um processo cíclico, contínuo e ininterrupto, de atividades interligadas e complementares tomadas por diferentes instâncias de organização governamental, voltadas a viabilizar os objetivos preestabelecidos em planos ordenados e sequenciais. É o instrumental destinado à adoção da solução mais racional dentre as alternativas. Por isso, deve ser entendido como um processo contínuo de negociação de conflitos sociais entre o Estado e a sociedade, mediado pelo Parlamento, do qual se obtém o avanço do exercício da cidadania e, ultima ratio, da democracia. Planejar é fixar metas e prazos aferíveis, assim como os meios para alcançá-las e torná-las transparentes pelo instrumento legislativo de orçamento.

$\mathrm{O}$ orçamento atua como um filtro que aspira receitas provenientes da renda de particulares e as devolve com distribuição diferente - espera-se, mais equânime. Abaixo da Constituição, as leis orçamentárias são os atos político-jurídicos mais relevantes no desenvolvimento da nação, pois é por intermédio delas que se promovem a superação de desigualdades e o equilíbrio da economia (FERREIRA; OLIVEIRA, 2017; HARADA, 2007; MATIAS-PEREIRA, 2010). Por isso, destacam-se a importância de pensar o planejamento público com base no pressuposto de coexistência da pluralidade que permeia o espaço urbano, como registra Xavier (2018), e a necessidade de superar o modelo de construção orçamentária confinado ao Poder Executivo.

A CF/88 resgatou a prerrogativa do Legislativo de participar do processo de planejamento por meio de emendas às leis orçamentárias. No entanto, o declínio das funções legislativas, por longo tempo, gerou distanciamento dos parlamentares das questões atinentes ao orçamento público, o que, associado aos baixos níveis de transparência e à assimetria de informações, torna pouco significativa a participação do Legislativo no planejamento governamental.

\subsection{O Parlamento no planejamento público}

As políticas públicas são definidas em decorrência de disputas políticas, uma vez que o interesse público, compreendido como interesses coletivos legítimos e conflitantes, não é unívoco. Elas são produto (output) da atividade política, do conjunto de decisões e ações relacionadas à alocação imperativa de valores que, no planejamento público, resulta em leis orçamentárias que elegem prioridades a serem financiadas pelos recursos públicos (CORRALO, 2008; MATIAS-PEREIRA, 2010; RIBEIRO; BLIACHERIENE, 2013). 
A integração da sociedade no processo decisório, garantida pela $\mathrm{CF} / 88$, a LRF$^{1}$ e o Estatuto das Cidades ${ }^{2}$, deriva da crise de governança e de governabilidade pela ineficiência e falta de transparência do modelo burocrático que, a partir da década de 1980, instigaram a formação de modelos teóricos voltados à descentralização, à responsabilização de gestores (responsiveness e accountability), à gestão por resultados, ao controle social e à participação social. Nesse contexto, a participação direta da sociedade apresenta-se como uma ferramenta a serviço do planejamento público. Sua adoção reduz déficits de legitimidade dos modelos políticos e déficits de informação dos modelos gerenciais tradicionais. Com a participação popular, gradativamente serão substituídos os interesses pessoais e de grupos de pressão eventuais pelas soluções de estrutura permanente e coletivas (MATIAS-PEREIRA, 2010; RIBEIRO;BLIACHERIENE, 2013; XAVIER, 2018).

Como instrumento de gestão pública, porém, a participação tem fatores limitantes. O primeiro deles é o caráter dispersivo de iniciativas que precisam ser coordenadas em rede com os governos locais e de outros níveis para alçar efetividade. $\mathrm{O}$ segundo remete à falta de regras contínuas de participação na formulação das políticas públicas, o que fragmenta as experiências. Além disso, a participação pode difundir errônea sensação de diluição de responsabilidades por ausência de institucionalização. Ao mesmo tempo, máxime, o excesso de institucionalização pode gerar burocratização e restringir a participação. E, no caso brasileiro, há fatores adicionais: o clientelismo político; o assistencialismo; as dificuldades no acesso às informações públicas; e a falta de cultura de participação e fiscalização popular (RIBEIRO; BLIACHERIENE, 2013).

A pesquisa de Pupo e Bueno (2012) revela que a representação popular em conselhos gestores de políticas públicas também é frágil em razão da ausência de bases sociais e pode criar "armadilhas de representação" para fundamentar decisões políticas que privilegiam grupos de interesses. Isso implica inferir que a participação popular, em que pese necessária, apresenta vieses ao expressar a vontade da sociedade e não se sobrepõe à representação política pelos parlamentares nem a exclui. Mesmo no contexto de orçamento participativo é:

[...] recomendável para a sociedade que, além de desenvolver esforços no sentido de atuar de forma legítima e incisiva em relação ao acompanhamento do processo orçamentário, sejam exercitadas as atribuições constitucionais do Poder Legislativo, com vistas a

\footnotetext{
1. Inciso I do $\$ 1^{\circ}$ do art. 48 da Lei Complementar Federal $n^{\circ}$. 101, de 4 de maio de 2000.

2. Art. 44 da Lei Federal nº. 10.257, de 10 de julho de 2001.
} 
fortalecer e estender a capacidade de fiscalização e controle da representação política, tendo como pressuposto que a crítica deve ser desdobrada em ação corretiva (MATIAS-PEREIRA, 2010, p. 319).

O planejamento que vem sendo construído no Brasil, todavia, persiste centralizado e hierarquizado, pois "o Poder Executivo não é apenas o detentor do monopólio da força física coercitiva. Ele vem, ao longo do tempo, afirmando hegemonia dentro do sistema político, obscurecendo ou dificultando a ação e o papel dos demais poderes tradicionais do Estado" (MATIAS-PEREIRA, 2010, p. 316). Com isso, relegam-se à instância de representação popular o papel coadjuvante e uma posição de desvantagem em relação ao Poder Executivo que, em regra, monopoliza informações e dispõe de corpo técnico especializado mais preparado para impor decisões unilaterais.

Atribui-se, de fato, ao Poder Executivo a iniciativa privativa dos projetos de lei relacionados ao orçamento público3 ${ }^{3}$. Contudo, é do Poder Legislativo a competência para dispor sobre as leis orçamentárias ${ }^{4}$, historicamente os instrumentos que disciplinam o grau de arbítrio do governante. A fragilidade da accountability do orçamento, cujo órgão de controle é o Legislativo, é apontada, inclusive, como uma das causas da baixa efetividade no desempenho do Poder Executivo na realização do orçamento pela ausência de desafios ao agente (SANTISO, 2015). Por essas funções típicas de fiscalização e controle, portanto, deve ser inquestionável a legitimidade do parlamentar para discutir e discordar de políticas implementadas pela Administração, propondo, com a autoridade que lhe é investida, as modificações necessárias (CORRALO, 2008).

O constituinte de 1988 garante a prerrogativa parlamentar de propor emendas aos projetos de lei orçamentária. $\mathrm{O} \$ 2^{\circ}$ do art. 35 do Ato das Disposições Constitucionais Transitórias (ADCT), ao fixar o prazo para que o Poder Legislativo devolva os projetos de leis orçamentárias para "sanção”, ao mesmo tempo que impede, teoricamente, a rejeição total da proposta, assegura ao Parlamento a capacidade de emendar as leis orçamentárias. Não haveria então sentido lógico-racional de submissão da proposta à apreciação se tivesse de ser obrigatoriamente aprovada na íntegra, independentemente do crivo político-racional do povo representado. É o poder de emendar a proposta orçamentária que torna injustificável a rejeição total do projeto de lei (GIACOMONI, 2010).

Contudo, a hegemonia pelo Poder Executivo no planejamento das ações e da despesa governamental, a assimetria de informações e o déficit de conhecimento

\footnotetext{
3. Inciso XXIII do art. $84, \mathrm{CF} / 88$.

4. Incisos II e IV do art. 48, CF/88.
} 
técnico sobre o sistema de contabilidade pública e de classificações orçamentárias fazem com que as emendas parlamentares sejam uma tarefa tormentosa. Os maiores obstáculos às emendas são registrados nos projetos de PPA e LDO em razão tanto das particularidades dos programas do plano (denominação, objetivo, público-alvo, prazo, indicador, índice recente/desejado e fonte) e ações (tipo, descrição da ação, do produto, unidade responsável e quantidades anuais) como da complexidade das prioridades e metas constantes na LDO e seus anexos(CORRALO, 2008).

Além dessas dificuldades técnicas, o poder de emendar as propostas orçamentárias é condicionado à observância de critérios normativos derivados da CF/88 e da Lei Federal n. 4.320, de 17 de março de 1964, cuja finalidade é equilibrar a interação do Legislativo no orçamento com a iniciativa que é reservada ao Poder Executivo e garantir, assim, exequibilidade do planejamento público. Os critérios condicionantes da participação dos parlamentares no sistema orçamentário variam de acordo com a espécie da lei orçamentária e, em comparação com o regime da ordem constitucional anterior, o campo de atuação do Poder Legislativo atualmente é bastante amplo (HARADA, 2007).

\subsection{Emendas parlamentares no PPA}

O PPA, a principal ferramenta de planejamento público, uma vez que orienta e vincula a elaboração dos demais planos e programas públicos, tem como grande objetivo ter ações planejadas, transparentes e participativas do Poder Público (CORRALO, 2008). É o instrumento que engloba todas as ações do governo formuladas em diretrizes para as finanças públicas em médio prazo (quatro anos), identificando os recursos disponíveis e estabelecendo, em síntese, as despesas por função, subfunção e programa de governo. Por meio do PPA, é definida a política orçamentária que orientará a ação governamental e o planejamento para alcançar objetivos de redução de desigualdades regionais e sociais, em conjunção com os investimentos que serão revertidos em benefícios à sociedade (MATIAS-PEREIRA, 2010).

$\mathrm{Na}$ ausência da lei complementar referida na $\mathrm{CF} / 88$, o regramento que lhe é aplicável se encontra previsto diretamente na Constituição e em dispositivos esparsos que tangenciam o PPA, como a LRF e o Estatuto da Cidade. À vista do disposto no $\S 7^{\circ}$ do art. 166, da CF/88, são aplicadas aos projetos de leis orçamentárias, naquilo que não contrariem o contido na seção especial, as mesmas regras do processo legislativo ordinário.

As emendas são proposições acessórias que visam à alteração de projetos de lei. Os tipos de proposição acessória são definidos interna corporis pelos Regimentos das Casas Legislativas e, em geral, são: i) aditivas, quando acrescentam dispositivos do texto da proposta; ii) supressivas, quando suprimem dispositivos do texto 
original; ou iii) redacionais/modificativas, quando alteram a redação de dispositivos já constantes no plano de lei. As emendas chamadas substitutivas assumem a condição de nova proposição por substituírem a originária e, por isso, encontram-se no limiar entre emenda (acessório) e proposição principal. Podem ser apresentadas em projetos de iniciativa exclusiva, concorrente ou popular (BRUNO, 2007).

São, porém, inadequadas as emendas que versem sobre assunto diverso daquele tratado na proposição principal por razões de coerência lógica e de técnica legislativa. Além disso, nas hipóteses de emendas às proposições de iniciativa exclusiva do Poder Executivo, por força do art. 63 da CF/88, é vedado o aumento da despesa prevista. Essa restrição, no entanto, não se revela uma barreira intransponível, já que no PPA se veicula o orçamento por programas.

A cada programa correspondem um objetivo, um indicador que quantifica a situação que o programa seja destinado a modificar e produtos (bens e serviços) necessários para alcançar o objetivo. Em seguida, são identificadas as ações relacionadas a cada programa, as quais assumem a forma de atividades, projetos ou operações especiais, e seus valores, metas e unidades responsáveis devem ser devidamente descritos. A cada ação somente pode ser associado um produto, que será quantificado em unidade de medida e dará origem à meta (CONTI, 2010). Em razão do amplo espectro do planejamento orçamentário, essas informações devem, por pressuposto, ser detalhadas, transparentes e consistentes o suficiente para subsidiar o processo decisório de alocação de recursos (MATIAS-PEREIRA, 2010).

Além das normas comuns do processo legislativo ordinário, as emendas parlamentares ao PPA submetem-se apenas a uma condição especial, indicada no $\$ 2^{\circ}$ do art. 166 da CF/88, qual seja, o prazo regimental para sua apresentação à Comissão competente para emitir parecer de admissibilidade. Conclui-se, então, que a correção de assimetrias de informação e a capacitação das Casas Legislativas em prol do equilíbrio técnico entre os Poderes seriam capazes de superar as dificuldades experimentadas pelos parlamentares nas interações com a proposta de PPA e agregar diferentes perspectivas ao debate e à formação do planejamento público.

\subsection{Emendas parlamentares na LDO}

A LDO representa efetiva e importante inovação da área de orçamentação governamental. Ela tem a função de orientar a elaboração da LOA, servindo de elo com o PPA (GIACOMONI, 2010; PALUDO, 2019). Pela LDO são definidas orientações para que o Poder Executivo elabore o orçamento anual. Sua relevância é associada à função de tornar mais transparente e ampliar a participação do Legislativo no processo orçamentário. A LDO é o instrumento que 
apresenta a situação das finanças públicas e colhe, antes da elaboração da proposta do orçamento anual, as contribuições do Parlamento para orientar sua confecção (BRUNO, 2007; GIACOMONI, 2010).

As emendas parlamentares à LDO submetem-se, também, à limitação temporal para apresentação à Comissão Parlamentar e à obrigatoriedade de guardar pertinência lógica com a proposição principal e observar a técnica legislativa. Quanto à vedação de aumento de despesa, a parte final do inciso I do art. 63 da CF/88 excepciona as emendas relacionadas com a LDO e a LOA, ou seja, as autoriza. A CF/88 prevê, todavia, no $\$ 4^{\circ}$ do art. 166, uma condicionante especial para aprovação de emendas à LDO: a compatibilidade com o PPA.

1.5 Emendas parlamentares na LOA

O “produto final” do processo orçamentário é a LOA. Sua função é detalhar as estimativas de receitas e a previsão de despesas, embora possa excepcionalmente dispor também sobre a abertura de créditos suplementares e a contratações de crédito. Trata-se de norma vinculada e subordinada, por compatibilidade impositiva, tanto ao PPA como à LDO (PALUDO, 2019). A revalorização do orçamento anual pela $\mathrm{CF} / 88$ é fruto do princípio da universalidade, que exige a efetiva demonstração de todo o fluxo de receitas e despesas públicas para o exercício financeiro (GIACOMONI, 2010; HARADA, 2007). É conhecida como a "lei dos meios", por ser a via necessária para garantir os recursos orçamentários destinados a realizar planos, programas e projetos. Nenhuma despesa pública pode ser executada sem a correspondente autorização na LOA (PALUDO, 2019).

As emendas parlamentares à LOA são as que apresentam o conjunto de condicionantes mais complexo entre as leis orçamentárias. Os limites da intervenção parlamentar estão definidos no $\$ 3^{\circ}$ do art. 166, da CF/88. Da norma infere-se que há três espécies de emendas parlamentares autorizadas em face do orçamento anual: i) de texto, quando alteram a redação do texto do projeto ou de seus quadros e tabelas; ii) de receita, quando modificam a estimativa de receita; e iii) de despesas, quando aumentam o valor das dotações propostas. Quanto às emendas de despesas, ainda que sejam admitidas, o inciso II do art. 166 exige que seja demonstrada a origem dos recursos para suportá-las.

Portanto, as emendas de despesas na LOA devem ser: i) de remanejamento, quando o acréscimo ou inclusão é acompanhado de anulação de outras dotações equivalentes; ii) de apropriação, quando o acréscimo ou inclusão é acompanhado de anulação de reserva de recursos (reserva de contingência); ou iii) de cancelamento, quando se propõe apenas o cancelamento de uma despesa da proposta (GIACOMONI, 2010; PALUDO, 2019). 
Nos dois primeiros casos concentram-se as dificuldades dos parlamentares na apresentação das emendas. Isso porque se faz necessário apontar a classificação completa da despesa que se pretende adicionar ao orçamento. No caso de remanejamento, devem ser indicados desde o órgão/unidade orçamentária até o elemento da despesa tanto da rubrica da qual se anulam as dotações como da rubrica à qual se destinam. No caso de novas despesas, devem ser criados desde o novo programa, com projetos e atividades diferenciados dos demais, até o elemento da despesa. Qualquer equívoco no extenso detalhamento da classificação da despesa impede sua execução; suspendem-se os recursos, sem destinação específica, que poderão ser utilizados apenas mediante créditos adicionais. Além disso, as emendas somente podem indicar como fonte de recursos as dotações já consignadas na proposta, sob pena de afronta à receita estimada; e, pelo princípio do equilíbrio, há ainda a vedação à anulação de dotações de despesas que constituem compromissos contínuos de caráter compulsório, como despesas de pessoal, serviço da dívida e transferências tributárias constitucionais (CORRALO, 2008).

Outras limitações às emendas parlamentares na LOA são previstas no art. 33 da Lei Federal n. 4.320, de 17 de março de 1964. A recepção dessa lei pela CF/88, porém, impõe um exercício de interpretação conforme. Guardam compatibilidade com a Constituição a alínea "a”, que contém o mesmo critério previsto no inciso III do $\S 3^{\circ}$ do art. 166 da Carta, e a alínea “c”, congruente com o princípio da separação de poderes, já que os serviços públicos são atividades administrativas do Poder Executivo sobre os quais o Legislativo não pode inovar. A alínea "d" sofreu revogação tácita pelos artigos 26 a 28 da LRF. Já o disposto na alínea "b” suscita maior digressão porque praticamente impossibilita a apresentação de emendas parlamentares sobre obras públicas e, por questão de coerência lógica, seria aplicável também ao Executivo, inviabilizando projetos futuros. Em razão da desproporcionalidade dessa condicionante em relação à finalidade de otimização de recursos públicos, sustenta-se, pois, a inconstitucionalidade desse dispositivo (CORRALO, 2008).

Além desse conjunto de critérios específicos, as emendas parlamentares submetem-se à limitação temporal para sua apresentação à comissão competente, no quesito de pertinência lógica e de técnica legislativa, e devem, obrigatoriamente, guardar compatibilidade com o PPA e a LDO.

\subsubsection{Emendas parlamentares impositivas}

Mesmo com a retomada das prerrogativas para emendar as propostas orçamentárias e o crescimento do interesse dos parlamentares sobre as finanças públicas, o caráter autorizativo do orçamento suscita descrédito à fase de apreciação pelo Legislativo tratada como mera formalidade (GIACOMONI, 2010; HARADA, 2007). 
Nessa condição autorizativa, o orçamento, apesar de submetido ao crivo do Legislativo para emendas e aprovação, retorna ao Poder Executivo com alta carga de discricionariedade, especialmente em relação às despesas variáveis cujos créditos são limitativos e não imperativos; estas diferenciam-se das despesas fixas, cuja execução é obrigatória por estarem previstas na Constituição ou em outras espécies de leis que criam, materialmente, deveres para o Estado (GIACOMONI, 2010).

$\mathrm{Na}$ ausência de transparência e de instrumentos eficientes de controle, inclusive sobre a abertura de créditos por anulação das despesas aprovadas na fase legislativa, e diante das insuficiências de capacidade técnica para acompanhar, controlar e avaliar a execução orçamentária, a participação do Poder Legislativo no processo decisório das políticas públicas mostra-se fragilizada. Esses déficits entre o órgão competente para elaboração e execução e o órgão incumbido de exercer o controle e a fiscalização terminam por produzir uma disfunção preocupante no processo orçamentário que compromete a eficiência e a eficácia dos gastos públicos (MATIAS-PEREIRA, 2010).

Para a ampliação da participação do Legislativo, Giacomoni (2010) sugere duas soluções: a primeira inspirada no sistema estadunidense de rescission, por meio do qual todo cancelamento de dotação orçamentária dependeria de prévia autorização legislativa; e a segunda resultante da adoção de meios para possibilitar maior ingerência do Legislativo na programação financeira de desembolsos do Executivo. Seria imprescindível, porém, que o Legislativo estivesse devidamente capacitado para absorver as demandas e responder a elas com celeridade, no primeiro caso, ou para acompanhar a execução orçamentária, no segundo.

A aprovação das Emendas Constitucionais $n^{\circ}$. 86, de 17 de março de 2015, e $\mathrm{n}^{\mathrm{o}}$. 100, de 26 de junho de 2019, direciona o sistema à segunda solução, ampliando a ingerência sobre a execução. Nessa senda, o constituinte derivado concedeu ao Legislativo a prerrogativa de aprovar emendas impositivas no orçamento público até um limite percentual das receitas. Por meio delas, as despesas variáveis indicadas pelos parlamentares são transferidas da categoria de ações facultadas para ade despesas fixas, de execução obrigatória. Os benefícios dessa alteração, no entanto, são controversos. Para os defensores do jogo político, a emenda parlamentar individual impositiva enfraquece o processo articulatório inerente à arena política, desconsiderando, por vezes, as emendas do tipo pork barrel $l^{5}$ utilizadas com objetivos eleitorais, como apontam Baião e Couto (2017). Por outro lado, a imposição de execução apenas quanto às emendas parlamentares, e não ao orçamento

5. Expressão da literatura internacional que indica particularização de políticas distributivas pela utilização de emendas parlamentares ao orçamento como mecanismo de captação de votos no processo eleitoral. 
como um todo, não garante a execução de políticas públicas de interesse do povo (shareholder). Opostamente, a reforma constitucional remete mais à tensão política entre os Poderes do que à finalidade do orçamento enquanto instrumento fundamental do Estado - e não de governos - para realizar direitos fundamentais (FERREIRA; OLIVEIRA, 2017).

A Emenda Constitucional $n^{\circ} .86$, cujos efeitos se iniciaram depois da execução orçamentária do exercício de 2014, estabeleceu o percentual de 1,2\% da receita corrente líquida prevista no projeto encaminhado pelo Poder Executivo a ser alocado no orçamento por emendas parlamentares individuais. Já a Emenda Constitucional n. 100, com efeitos após a execução orçamentária do exercício financeiro de 2020, destina $1 \%$ da receita corrente líquida realizada no exercício anterior para emendas de bancadas parlamentares.

As emendas impositivas, entretanto, devem observar alguns critérios e submetem-se a uma condição resolutiva. Metade do percentual destinado às emendas individuais deve ser alocada em ações e serviços públicos de saúde, vedado o pagamento de pessoal ou de encargos sociais com tais recursos. As emendas de bancada, quando versarem sobre o início de investimentos com duração superior a um exercício financeiro ou de execução já iniciada, devem ser objeto de emenda pela mesma bancada, a cada exercício, até sua conclusão. Em todos os casos, as emendas impositivas deixam de ser obrigatórias quando há impedimentos de ordem técnica.

A pesquisa de Bonfim e Sandes-Freitas (2019) aponta que, apesar da disciplina de emendas impositivas pela Emenda Constitucional n. 86, o Executivo federal manteve a prerrogativa de uso de instrumentos para contornar as prioridades indicadas pelos parlamentares durante a execução orçamentária. Com isso, persistia o controle deste sobre todas as fases do ciclo orçamentário, incluindo a legislativa.

A Emenda Constitucional $n^{\circ} .100$ tornou expresso o dever de realizar as programações orçamentárias de despesas primárias discricionárias com o fito de entregar bens e serviços à sociedade, denotando tendência à contenção da discricionariedade do Executivo na execução orçamentária. A obrigação, no entanto, nos termos do §11 do art. 165, pode ser afastada em casos de não atendimento das metas fiscais ou de limites de despesas, mas não impede o cancelamento necessário à abertura de créditos adicionais e tampouco se aplica a impedimentos de ordem técnica devidamente justificados, cabendo à lei complementar regulamentar os procedimentos relacionados atais impedimentos.

\section{Procedimentos metodológicos}

Este trabalho volta-se à investigação de fenômenos contemporâneos, associados a uma situação da realidade político-social organizada com implicações 
práticas, o que justifica a adoção da pesquisa aplicada com enfoque descritivo de caráter bibliográfico e documental. Delineado como estudo de caso, tem por objetivo conhecer a vivência de uma realidade e a esse respeito promover uma análise e discussão (CRESWELL, 2010; GIL, 2008; GODOY, 1995). O método empregado é o estatístico descritivo, orientado a identificar fenômenos e medir sua importância e variações. A pesquisa buscou reduzir fatos políticos complexos a medidas quantitativas simplificadas para obter entendimento empírico a respeito da participação dos parlamentares no sistema orçamentário (GIL, 2008; MARCONI e LAKATOS, 2003).

O Parlamento do município de Curitiba foi selecionado como objeto de estudo representativo pela associação dos seguintes critérios: i) econômico, haja vista a inter-relação entre as finanças públicas e a economia; e ii) prático. Como critério econômico, consoante estudo de Lima (LIMA; REZENDE, 2019) sobre a relação entre a carga tributária e o PIB, adota-se o índice de Produto Interno Bruto (PIB) das unidades da federação, apurado pelo Instituto Brasileiro de Geografia e Estatística (IBGE, 2016), com vistas a identificar as cidades com as maiores capacidades de arrecadação de receitas e possibilidades de reversão em políticas públicas para promover o desenvolvimento local por emendas parlamentares.

As duas cidades brasileiras de maior PIB, São Paulo e Rio de Janeiro, exibem resultados superiores à média desse índice entre os estados-membros. Em razão da acentuada vantagem econômica, essas cidades são dissociadas da escala municipal proposta na pesquisa em razão das dimensões estaduais em termos orçamentário-financeiros. Em seguida, as cidades de maior PIB são Belo Horizonte e Curitiba, e, nesta última, a Câmara Municipal (CMC) disponibiliza acesso público, por meio da internet, à ferramenta de acompanhamento de proposições legislativas que permite a extração de relatórios de emendas parlamentares quanto à espécie, iniciativa e status, para os fins quantitativos e descritivos propostos. Essa disponibilidade de dados foi, então, adotada como critério prático de seleção de amostra para o estudo.

Os dados coletados remetem às emendas parlamentares apresentadas pelos vereadores entre os anos de 2013 e 2019, correspondendo à $16^{\mathrm{a}}$ e à $17^{\mathrm{a}}$ legislaturas, esta ainda em curso. O recorte latitudinal do estudo é motivado pelas alterações promovidas pelas Emendas Constitucionais $\mathrm{n}^{\circ} .86$ e $\mathrm{n}^{\circ}$. 100, com o objetivo de avaliar seus reflexos na atividade dos parlamentares.

Considerando que o ciclo orçamentário não se confunde com o exercício financeiro e que as emendas são apresentadas na fase legislativa, antes da vigência da lei orçamentária (PALUDO, 2019; RIBEIRO; BLIACHERIENE, 2013), no período pesquisado foram discutidas e aprovadas na CMC dezesseis leis orçamentárias: dois PPAs, sete LDOs e sete LOAs. Foram obtidos relatórios de emendas relacionadas a 
esses projetos de lei no banco público de dados disponibilizado pela CMC em seu sítio eletrônico oficial, por meio da ferramenta "Sistema de Proposições Legislativas - SPL II”(CURITIBA, [s.d.]), com a indicação da "espécie” de proposição (emenda) e do "código da proposição principal ou alvo", qual seja, o número de registro dos projetos de lei orçamentárias. A coleção de dados levantados é apresentada em Apêndice na forma de documento complementar deste trabalho.

\section{Resultados e discussões}

Os resultados da pesquisa demonstram que todos os dezesseis projetos de leis orçamentárias pesquisados receberam emendas parlamentares. Foram apresentadas 4.275 delas, das quais 3.957 emendas individuais e 318 coletivas ${ }^{6}$. Destas, foram aprovadas 3.935, ou seja, 92\% do total das propostas. Nenhuma emenda parlamentar aprovada foi vetada pelo Executivo no período em que se desenvolveu a pesquisa.

Os dados evidenciam, porém, que o maior volume de emendas parlamentares se concentra nas LOAs, com $97 \%$ do total de propostas. A Tabela 1 demonstra que houve incremento relevante no número de emendas parlamentares apresentadas nos anos de 2018 e 2019, respectivamente, às LOAs de 2019 e 2020, o que indica que a normatização das emendas impositivas estimuloua participação parlamentar no planejamento público, como previsto por Giacomoni (2010).

\begin{tabular}{c|c|c|c}
\hline Ano de apresentação & PPA & LDO & LOA \\
\hline 2013 & 42 & 30 & 650 \\
\hline 2014 & - & 3 & 505 \\
\hline 2015 & - & 2 & 496 \\
\hline 2016 & - & 18 & 442 \\
\hline 2017 & 17 & 11 & 490 \\
\hline 2018 & - & 4 & 726 \\
\hline 2019 & - & 5 & 834 \\
\hline
\end{tabular}

Tabela 1. Evolução quantitativa de emendas parlamentares aos projetos de leis orçamentárias apresentadas entre 2013 e 2019

Fonte: Elaborada pelos autores com base em pesquisa documental (CURITIBA, [s.d.]).

6. Emendas de iniciativa conjunta de vereadores, de bancadas parlamentares e da Comissão de Economia Finanças e Fiscalização. Não foram consideradas as emendas apresentadas pela Comissão Executiva, órgão colegiado de gestão administrativa, haja vista se referirem à proposta orçamentária do Legislativo cuja competência para elaboração lhe é atribuída originariamente. 
Além da concentração quase exclusiva na LOA, as emendas parlamentares do período pesquisado são, majoritariamente, aditivas. A Tabela 2 demonstra o quantitativo de emendas parlamentares de acordo com sua tipificação e, consequentemente, os efeitos esperados pelo proponente. As emendas aditivas, destinadas ao aumento de despesas por remanejamento ou apropriação, representam mais de $99 \%$ das propostas dos parlamentares.

\begin{tabular}{|c|c|c|c|c|}
\hline Legislatura & Referência & Aditivas & Modificativas & Supressivas \\
\hline \multirow{9}{*}{$16^{a}(2013 / 2016)$} & LDO 2014 & 27 & 3 & 0 \\
\hline & PPA 2014/2017 & 30 & 11 & 1 \\
\hline & LOA 2014 & 650 & 0 & o \\
\hline & LDO 2015 & 3 & 0 & 0 \\
\hline & LOA 2015 & 504 & 1 & o \\
\hline & LDO 2016 & 0 & 2 & o \\
\hline & LOA 2016 & 496 & 0 & 0 \\
\hline & LDO 2017 & 15 & 3 & 0 \\
\hline & LOA 2017 & 441 & 1 & 0 \\
\hline \multirow{7}{*}{$17^{\mathrm{a}}(2017 / 2020)$} & LDO 2018 & 11 & 0 & 0 \\
\hline & PPA 2018/2021 & 6 & 11 & 0 \\
\hline & LOA 2018 & 490 & 0 & 0 \\
\hline & LDO 2019 & 3 & 0 & 1 \\
\hline & LOA 2019 & 726 & 0 & 0 \\
\hline & LDO 2020 & 5 & 0 & 0 \\
\hline & LOA 2020 & 833 & 1 & 0 \\
\hline
\end{tabular}

Tabela 2. Tipos de emendas apresentadas aos projetos de leis orçamentárias entre 2013 e 2019 Fonte: Elaborada pelos autores com base em pesquisa documental (CURITIBA, [s.d.]).

Esses elevados percentuais associados à LOA indicam que a participação do Legislativo no planejamento público ainda é condicionada pelo Poder Executivo, que "facilita" e delimita o espaço de intervenção parlamentar, promovendo reserva antecipada dos valores destinados à alocação pelos parlamentares. Essa "gerência" do Executivo sobre as emendas parlamentares pode, até mesmo, ser associada aos percentuais das receitas definidos para fins de emendas impositivas, sugerindo equivocadamente que a participação seria limitada àqueles valores. Essas deduções são alimentadas pela análise das emendas convertidas em lei no PPA e na LDO, nos quais não há emendas impositivas, que revelam um percentual de aprovação, em regra, expressivamente inferior (Tabela 3). 


\begin{tabular}{|c|c|c|c|c|}
\hline Legislatura & Referência & $\begin{array}{c}\text { Total de emendas } \\
\text { parlamentares }\end{array}$ & Aprovadas & $(\%)$ \\
\hline \multirow{9}{*}{$16^{a}(2013 / 2016)$} & LDO 2014 & 30 & 3 & 10,00 \\
\hline & PPA 2014/2017 & 42 & 4 & 9,52 \\
\hline & LOA 2014 & 650 & 574 & 88,31 \\
\hline & LDO 2015 & 3 & 0 & 0,00 \\
\hline & LOA 2015 & 505 & 484 & 95,84 \\
\hline & LDO 2016 & 2 & 2 & 100,00 \\
\hline & LOA 2016 & 496 & 402 & 81,05 \\
\hline & LDO 2017 & 18 & 8 & 44,44 \\
\hline & LOA 2017 & 442 & 433 & 97,96 \\
\hline \multirow{7}{*}{$17^{a}(2017 / 2020)$} & LDO 2018 & 11 & o & 0,00 \\
\hline & PPA 2018/2021 & 17 & 6 & 35,29 \\
\hline & LOA 2018 & 490 & 487 & 99,39 \\
\hline & LDO 2019 & 4 & 2 & 50,00 \\
\hline & LOA 2019 & 726 & 708 & 97,52 \\
\hline & LDO 2020 & 5 & 0 & 0,00 \\
\hline & LOA 2020 & 834 & 822 & 98,56 \\
\hline
\end{tabular}

Tabela 3.Percentual de aprovação das emendas nos projetos de leis orçamentárias votadas entre 2013 e 2019

Fonte: Elaborada pelos autores com base em pesquisa documental (CURITIBA, [s.d.]).

Essas variações resultam, a princípio, da tímida participação do Legislativo em tais propostas em decorrência do largo tempo de alijamento das funções legislativas em matéria orçamentária, como aponta a doutrina (MATIAS-PEREIRA, 2010; PALUDO; PROCOPIUCK, 2014). Mas há outros fatores que atuam no baixo percentual de aprovação das emendas ao PPA e à LDO associados às dificuldades técnicas e à assimetria de informações presentes no referencial teórico (CORRALO, 2008). No Gráfico 1, é possível visualizar as emendas ao PPA, evidenciando que $76 \%$ das propostas dos parlamentares para modificar a norma de regência do planejamento público foram inadmitidas pela Comissão de Economia, Finanças e Fiscalização por inadequações técnicas. No período, apenas $16 \%$ das propostas de emenda ao PPA foram aprovadas, denotando que o Poder Legislativo ainda não tem atuação expressiva no planejamento governamental de médio prazo.

No Gráfico 2, os dados das emendas parlamentares às LDOs são os que registram as maiores flutuações. A primeira, relacionada à quantidade de emendas apresentadas pelos parlamentares ao longo do período, oscila entre o máximo de trinta registradas na LDO de 2014 e o mínimo de duas na LDO de 2016. Nas propostas 
de LDO, também há elevado percentual de emendas inadmitidas pela Comissão (53\%). Já o percentual de aprovação é ligeiramente superior às emendas do PPA, representando $20 \%$ do total de emendas à LDO no período.

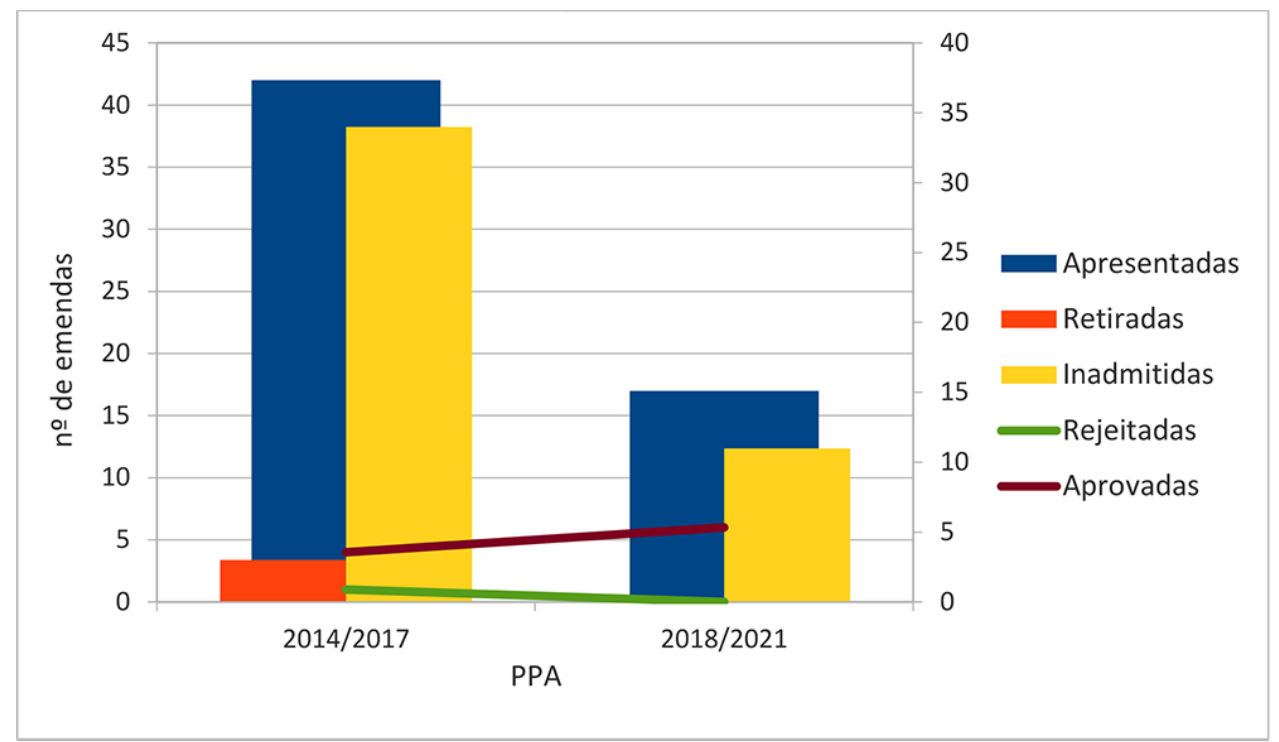

Gráfico 1. Emendas aos projetos de PPA de 2014-2017 e 2018-2021

Fonte: Elaborada pelos autores com base em pesquisa documental (CURITIBA, [s.d.]).

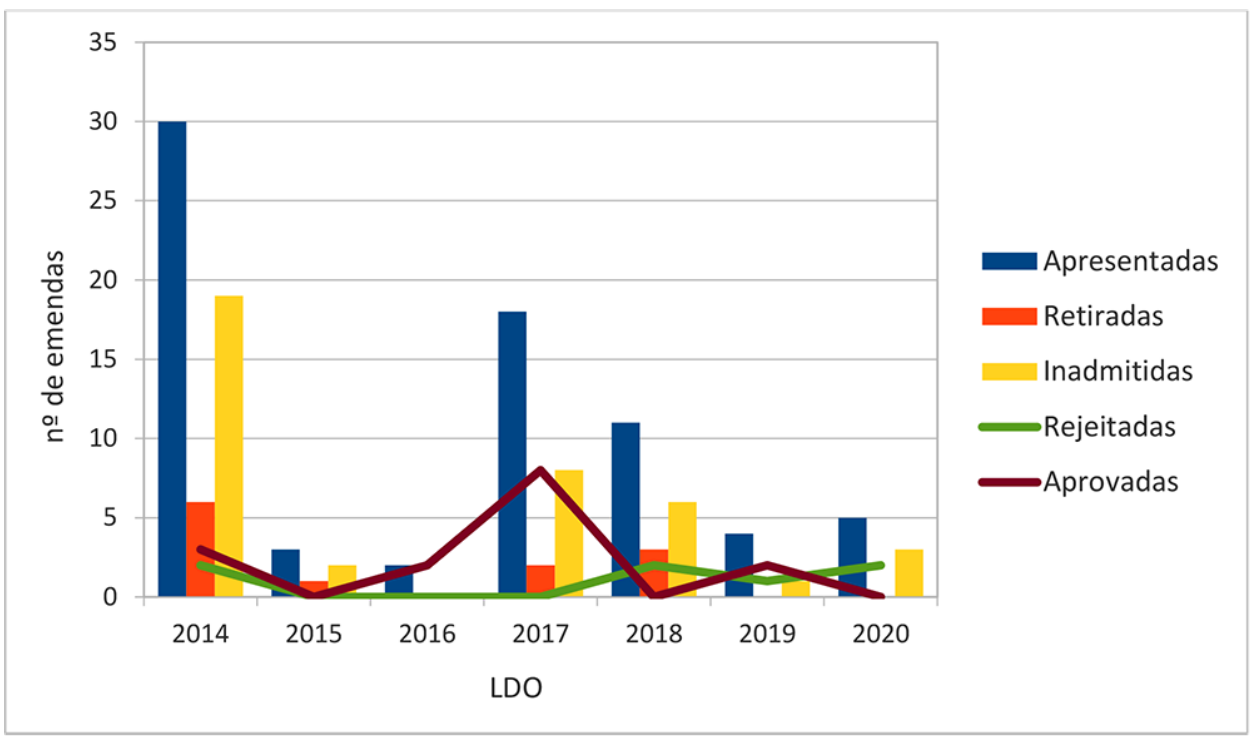

Gráfico 2. Emendas aos projetos de LDO de 2014 a 2020

Fonte: Elaborada pelos autores com base em pesquisa documental (CURITIBA, [s.d.]). 
As dificuldades técnicas, todavia, não são registradas nas emendas à LOA (Gráfico 3). Apesar de nesse processo residir o maior conjunto de critérios constitucionais e legais, as emendas à LOA apresentam os menores índices de inadmissibilidade perante a Comissão de Economia, Finanças e Fiscalização.

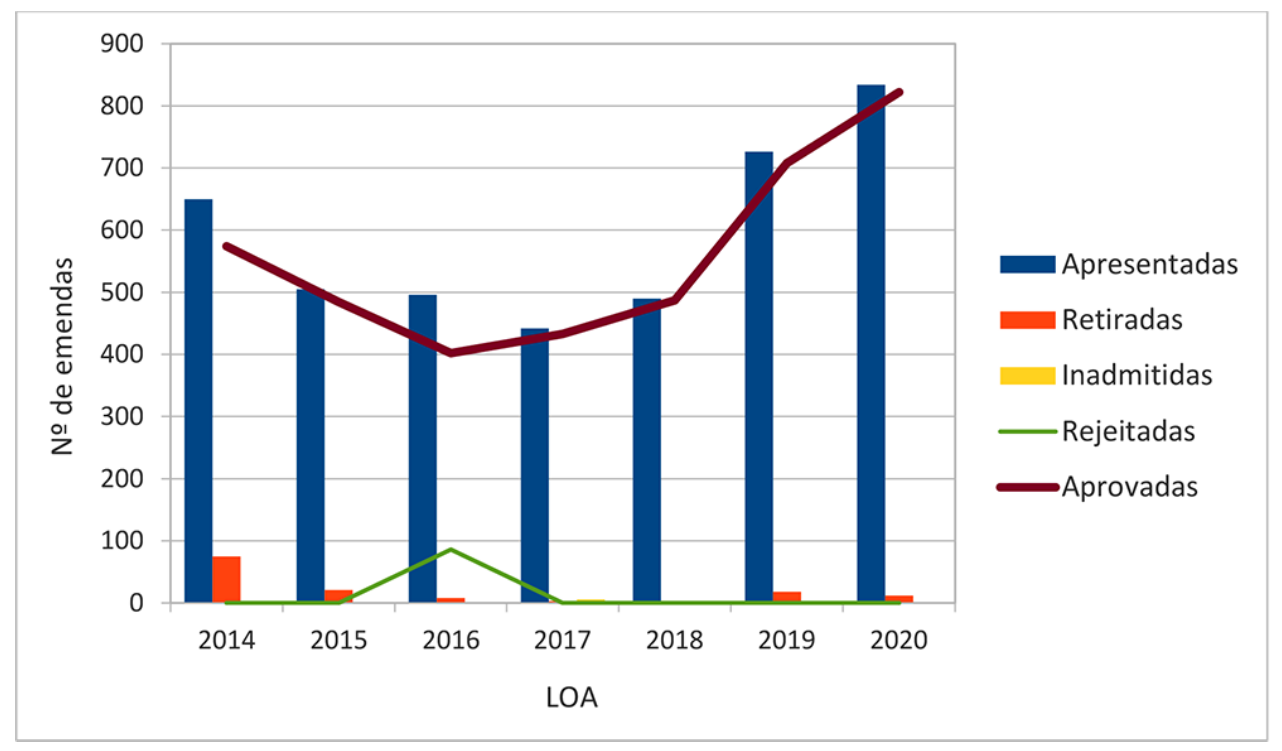

Gráfico 3. Emendas aos projetos de LOA de 2014 a 2020

Fonte: Elaborada pelos autores com base em pesquisa documental (CURITIBA, [s.d.]).

Dentre as 4.144 emendas parlamentares apresentadas às LOAs, apenas oito não tiveram a apreciação em Plenário admitida em razão de parecer contrário da Comissão. Essa assertividade das emendas à LOA, dissonante das intervenções nas demais leis orçamentárias, reforça a suposição de direcionamento técnico do Poder Executivo como fator determinante da participação do Legislativo.

\section{Considerações finais}

A pesquisa desenvolvida neste artigo releva que as intervenções do Legislativo se concentram na LOA, que é apenas a ponta de um longo processo de decisões tomadas previamente no PPA e na LDO. As emendas parlamentares são majoritariamente aditivas, o que denota sobrevalorização, pelo parlamentar, da inclusão de novas despesas com ações e obras de execução no curto prazo e pouca intervenção crítica nas propostas apresentadas pelo Executivo que poderiam ser revisadas por emendas modificativas ou supressivas.

Nos instrumentos de planejamento por excelência, PPA e LDO, a maioria das emendas foi inadmitida por questões técnicas. Isso aponta a persistência da hegemonia do Poder Executivo dentro do sistema político orçamentário que 
decorre da posição de desvantagem técnica do Parlamento e da assimetria de informações resultante da baixa qualidade da transparência empregada na elaboração dos orçamentos.

A aprovação das Emendas Constitucionais n. 86 e n. 100 revela em si uma dualidade. Ela estimula, de fato, a participação do parlamentar pela garantia de execução do orçamento, mas, de certa forma, também amplia o controle do Executivo sobre a fase legislativa em face da organização antecipada daquilo que poderá ser moldado pelos representantes do povo, mantendo-se o modelo hegemônico de construção. O empoderamento técnico dos Parlamentos para exercer as funções legislativas em matéria orçamentária seria revertido em benefício da sociedade pela entrega de um planejamento público plural e democrático, baseado em diversas perspectivas de soluções às demandas sociais e econômicas.

Dado que o conhecimento e a ciência não são finitos, o estudo realizado neste artigo não tem a pretensão de abordar o assunto à exaustão, mas busca contribuir com as pesquisas científicas sobre a fase legislativa do ciclo orçamentário, ainda escassas quando comparadas a outras fases do processo de planejamento público. Diante das transformações que as emendas parlamentares impositivas têm o potencial de produzir na sistemática de decisões públicas, o tema desponta como campo fecundo à investigação acadêmica. Sugere-se, por isso, sem a exclusão de outros, o aprofundamento de estudos no que tange aos meios de superação das insuficiências técnicas dos Legislativos municipais para subsidiar as decisões políticas dos parlamentares e a relação entre as demandas populares no orçamento participativo e emendas parlamentares.

\section{Referências}

BAIÃO, A. L.; COUTO, C. G. A eficácia do pork barrel: a importância de emendas orçamentárias e prefeitos aliados na eleição de deputados. Opinião Pública, v. 23, n. 3, p. 714-753, $1^{\circ}$ set. 2017.

BONFIM, R. W. L.; SANDES-FREITAS, V. E. V. de. Quem controla o orçamento? Apontamentos sobre o timing de liberação das emendas orçamentárias individuais. CAOS - Revista Eletrônica de Ciências Sociais, v. 2, n. 23, p. 139-156, 28 dez. 2019.

BRUNO, R. M. Lei de Responsabilidade Fiscal e orçamento público municipal. 2. ed. Curitiba: Juruá, 2007.

CEPAL. COMISSÃO ECONÔMICA PARA A AMÉRICA LATINA E O CARIBE. Plan de acción regional para implementación de la nueva agenda urbana en América Latina y el Caribe. Santiago: [s.n.], 2016. Disponível em: https://repositorio.cepal.org/bitstream/handle/11362/42144/2/S1800033_es.pdf. Acesso em: 17 set. 2019. 
COIMBRA, A. C. M.; KOPFER, K. R. Polo tecnológico de São José dos Campos: análise crítica da política pública municipal. Revista Brasileira de Planejamento e Desenvolvimento, v. 6, n. 2, p. 313-338, 2017. Disponível em: https://periodicos.utfpr.edu.br/rbpd/article/ view/5645/3573. Acesso em: 18 jan. 2020.

CONTI, J. Mauricio (coord.). Orçamentos públicos. São Paulo: Editora Revista dos Tribunais, 2010.

CORRALO, G. da S. O poder legislativo municipal: aportes teóricos e práticos para a compreensão e o exercício da função parlamentar nas câmaras de vereadores. Brasília, DF: Malheiros, 2008.

CRESWELL, J. W. Projeto de pesquisa: métodos qualitativo, quantitativo e misto. 3. ed. Porto Alegre: Artmed, 2010.

CURITIBA.CÂMARA MUNICIPAL. Sistema de proposições legislativas - SPL II. Disponível em: https://www.curitiba.pr.leg.br/atividade-parlamentar/projetos-de-lei. Acesso em: 23out. 2020.

DORNELLAS, E. D. Análise do sistema orçamentário na priorização de políticas públicas"secundárias": o caso de um município paranaense de pequeno porte. Curitiba: UTFPR, 2015. Disponível em: http://repositorio.utfpr.edu.br/jspui/handle/1/1431. Acesso em: 2 jan. 2020.

FERREIRA, F. G. B. de C.; OLIVEIRA, C. L. O orçamento público no Estado constitucional democrático e a deficiência crônica na gestão das finanças públicas no Brasil. Sequência: Estudos Jurídicos e Políticos, v. 38, n. 76, p. 183, 20 set. 2017.

FLORIDA, R. Cities are the engines of global progress: they can act as economic engines for entire countries. Poverty in focus, v. 13, Issue 3, December 2016. Brasília, DF: United Nations Development Programme. Disponível em: http://www.ipc-undp.org/pub/eng/ PIF37_A_new_urban_paradigm_pathways_to_sustainable_development.pdf. Acesso em: 17 set. 2019. [A new urban paradigm: pathways to sustainable development. The International Policy Centre for Inclusive Growth].

GIACOMONI, J. Orçamento público. 15. ed. São Paulo: Atlas, 2010.

GIL, A. C. Métodos e técnicas de pesquisa social. 6. ed. São Paulo: Atlas, 2008.

GODOY, A. S. Pesquisa qualitativa: tipos fundamentais. Revista de Administração de Empresas São Paulo, v. 35, n. 3, 1995.

HARADA, K. Direito financeiro e tributário. 16. ed. São Paulo: Atlas, 2007.

INSTITUTO BRASILEIRO DE GEOGRAFIA E ESTATÍSTICA (IBGE). Tabela 5938 - Produto Interno Bruto a preços correntes, impostos, líquidos de subsídios, sobre produtos a preços correntes e valor adicionado bruto a preços correntes total e por atividade econômica, e respectivas participações - referência 2011 a 2016. Disponível em: https://sidra.ibge. gov.br/tabela/5938\#resultado. Acesso em: 5 out. 2019.

LIMA, E. M.; REZENDE, A. J. Um estudo sobre a evolução da carga tributária no Brasil: uma análise a partir da Curva de Laffer. Interações (Campo Grande), v. 20, n. 1, p. 239, 21 mar. 2019. 
MARCONI, M.; LAKATOS, E. M. Fundamentos de metodologia científica. São Paulo: Atlas, 2003.

MATIAS-PEREIRA, J. Finanças públicas: a política orçamentária no Brasil. 5. ed. São Paulo: Atlas, 2010.

MOLETA, E. R. O papel do sistema orçamentário no avanço do planejamento e da governança pública na direção do estado. 2017. Curitiba: UTFPR, 2017. Disponível em: http://repositorio.utfpr.edu.br/jspui/handle/1/2895. Acesso em: 2 jan. 2020.

PALUDO, A. Orçamento público, AFO e LRF: teoria e questões. 9. ed. Rio de Janeiro: Forense, 2019.

PALUDO, A. V.; PROCOPIUCK, M. Planejamento governamental: referencial teórico, conceitual e prático. 2. ed. São Paulo: Atlas, 2014.

PUPO, S.; BUENO, L. M. de M. Entre avanços e retrocessos: as contradições ou armadilhas da participação no planejamento urbano participativo. Revista brasileira de estudos urbanos e regionais, v. 14, n. 1, p. 135, 31 maio 2012.

RIBEIRO, R. J. B.; BLIACHERIENE, A. C. Construindo o planejamento público: buscando integração entre política, gestão e participação popular. São Paulo: Atlas, 2013.

SANTISO, C. Why budget accountability fails? The elusive links between parliaments and audit agencies in the oversight of the budget. Revista de Economia Política, v. 35, n. 3, p. 601-621, 2015.

XAVIER, M. Lugar, pluralidade da existência e democracia. Revista brasileira de estudos urbanos e regionais, v. 20, n. 3, p. 506, 27 jul. 2018. 
Apêndice

\begin{tabular}{|c|c|c|c|c|c|c|c|c|c|c|c|c|c|}
\hline Legislatura & Referência & $\begin{array}{c}\text { Lei } \\
\text { Municipal } \mathrm{n}^{\circ} .\end{array}$ & $\begin{array}{c}\text { Processo } \\
\text { legislativo } \mathrm{n}^{\circ} .\end{array}$ & $\begin{array}{c}\text { Total de } \\
\text { emendas } \\
\text { parlamentares }\end{array}$ & $\begin{array}{c}\text { Emendas } \\
\text { individuais }\end{array}$ & $\begin{array}{l}\text { Emendas } \\
\text { coletivas }\end{array}$ & Aditivas & Modificativas & Supressivas & Retiradas & Inadmitidas & Rejeitadas & Aprovadas \\
\hline \multirow{8}{*}{$\begin{array}{c}16^{\mathrm{a}} \\
(2013 / 2016)\end{array}$} & LDO 2014 & $14.286,12 / 07 / 13$ & 013.00003 .2013 & 30 & 27 & 3 & 27 & 3 & 0 & 6 & 19 & 2 & 3 \\
\hline & PPA 2014/2017 & 14.371, 09/12/13 & 013.00012 .2013 & 42 & 33 & 9 & 30 & 11 & 1 & 3 & 34 & 1 & 4 \\
\hline & LOA 2014 & $14.397,30 / 12 / 13$ & 013.00013 .2013 & 650 & 577 & 73 & 650 & o & o & 75 & 1 & o & 574 \\
\hline & LDO 2015 & $14.485,04 / 07 / 14$ & 013.00003 .2014 & 3 & 3 & 0 & 3 & o & 0 & 1 & 2 & 0 & 0 \\
\hline & LOA 2015 & $14.585,30 / 12 / 14$ & 013.00011 .2014 & 505 & 485 & 20 & 504 & 1 & o & 21 & 0 & o & 484 \\
\hline & LOA 2016 & $14.781,30 / 12 / 15$ & 013.00008 .2015 & 496 & 474 & 22 & 496 & 0 & 0 & 8 & 0 & 86 & 402 \\
\hline & LDO 2017 & $14.881,07 / 07 / 16$ & 013.00001 .2016 & 18 & 17 & 1 & 15 & 3 & 0 & 2 & 8 & 0 & 8 \\
\hline & LOA 2017 & $15.013,27 / 12 / 16$ & 013.00004 .2016 & 442 & 419 & 23 & 441 & 1 & 0 & 3 & 6 & 0 & 433 \\
\hline \multirow{6}{*}{$\begin{array}{c}17^{\mathrm{a}} \\
(2017 / 2020)\end{array}$} & LDO 2018 & $15.046,10 / 07 / 17$ & 013.00002 .2017 & 11 & 11 & 0 & 11 & 0 & 0 & 3 & 6 & 2 & 0 \\
\hline & PPA 2018/2021 & $15.131,08 / 12 / 17$ & 013.00005 .2017 & 17 & 16 & 1 & 6 & 11 & o & o & 11 & 0 & 6 \\
\hline & LOA 2018 & $15.157,27 / 12 / 17$ & 013.00007 .2017 & 490 & 463 & 27 & 490 & 0 & 0 & 2 & $1^{*}$ & 0 & 487 \\
\hline & LDO 2019 & $15.269,06 / 07 / 18$ & 013.00001 .2018 & 4 & 2 & 2 & 3 & 0 & 1 & 0 & 1 & 1 & 2 \\
\hline & LDO 2020 & $15.469,05 / 07 / 19$ & 013.00002 .2019 & 5 & 5 & 0 & 5 & 0 & 0 & 0 & 3 & 2 & 0 \\
\hline & LOA 2020 & $15.587,26 / 12 / 19$ & 013.00009 .2019 & 834 & 760 & 74 & 833 & 1 & 0 & 12 & o & 0 & 822 \\
\hline & & & Total & 4275 & 3957 & 318 & 4240 & 33 & 2 & 154 & 92 & 94 & 3935 \\
\hline
\end{tabular}

Tabela 4. Emendas

Nota: *1 emenda classificada como "prejudicada"; **5 emendas classificadas como "aprovada pela Comissão".

REVISTA BRASILEIRA DE ESTUDOS URBANOS E REGIONAIS, V.22، E202036pt، 2020

https://doi.org/10.22296/2317-1529.rbeur.202036pt 


\section{Priscila Perelles}

Bacharel em Direito pela Pontifícia Universidade Católica do Paraná (PUC-PR). Mestranda em Planejamento e Governança Pública pela Universidade Tecnológica Federal do Paraná (UTFPR).

Email: priperelles@gmail.com

ORCID: 0000-0001-8650-5576

Contribuição de autoria: conceituação; curadoria de dados; análise formal; investigação/pesquisa; metodologia; administração do projeto; recursos; supervisão/ orientação; escrita - primeira redação; escrita - revisão e edição.

\section{Antonio Gonçalves de Oliveira}

Bacharel em Direito pelo Centro Universitário UniDomBosco (PR). Bacharel em Ciências Contábeis pela Universidade Federal do Paraná (UFPR). Mestre em Administração pela Universidade Mackenzie (SP). Doutor em Engenharia de Produção pela Universidade Federal de Santa Catarina (UFSC).

Email: agoliveira@utfpr.edu.br

ORCID: 0000-0002-4191-9406

Contribuição de autoria: conceituação; investigação/pesquisa; metodologia; supervisão/orientação; escrita - revisão e edição.

\section{Ivan Carlos Vicentin}

Bacharel em Administração pela Sociedade Paranaense de Ensino e Informática (Spei). Bacharel em Ciência da Computação pela Pontifícia Universidade Católica do Paraná (PUC-PR). Mestre em Administração pela Universidade Federal do Rio Grande do Sul (UFRGS). Doutor em Administração pela Universidade de São Paulo (USP).

Email: vicentin@utfpr.edu.br

ORCID: 0000-0002-7081-4005

Contribuição de autoria: conceituação; análise formal; investigação/pesquisa; supervisão/orientação; escrita - revisão e edição. 


\section{Rogério Allon Duenhas}

Bacharel em Ciências Econômicas pelo Centro Universitário Franciscano do Paraná (FAE). Mestre e doutor em Desenvolvimento Econômico pela Universidade Federal do Paraná (UFPR).

Email: rogerioduenhas@utfpr.edu.br

ORCID: 0000-0002-0766-0322

Contribuição de autoria: supervisão/orientação; escrita - revisão e edição.

Submissão: 13 de fevereiro de 2020.

Aprovação: 17 de setembro de 2020.

Como citar: PERELLES, P.; OLIVEIRA, A. G.; VICENTIN, I. C.; DUENHAS, R. A. A participação do Poder Legislativo no planejamento público municipal: análise das propostas de emendas parlamentares às leis orçamentárias de Curitiba. Revista brasileira de estudos urbanos e regionais. v. 22, E202036pt, 2020. DOI 10.22296/2317-1529.rbeur.202036pt

Artigo licenciado sob Licença Creative Commons CC BY 4.0.

https://creativecommons.org/licenses/by/4.o/deed.pt_BR 